\title{
Are Patients with Thrombocytopenia at Higher Risk for Adverse Outcomes after Hysterectomy for Benign Indications?
}

\author{
David Sheyn ${ }^{1}$, Ryan Darvish ${ }^{1}$, Lalitha Nayak ${ }^{2}$, Sara Myer ${ }^{3}$, Caitlin Clardige ${ }^{1}$, and Carol \\ Bretrschneider ${ }^{4}$
}

\author{
${ }^{1}$ MetroHealth Medical Center \\ ${ }^{2}$ Affiliation not available \\ ${ }^{3}$ Case Western Reserve University \\ ${ }^{4}$ Northwestern University
}

May 20, 2020

\begin{abstract}
Objective: To determine the risk of thrombocytopenia on postoperative complication following hysterectomy for benign indications. Design: Retrospective Cohort Setting: American College of Surgeons National Surgical Quality Improvement database. Population: Women undergoing hysterectomy by any route between 2014 and 2018 Methods: Patients stratified into three groups: normal platelet count, mild thrombocytopenia defined as a platelet count between 100 - 149 x 103 per microliter, and moderate thrombocytopenia defined as a platelet count between 50 x 99 x 103 per microliter. Three group comparison was performed using Kruskal-Wallis. If results were found to be statistically significant, then pairwise analysis was performed between reference group (normal platelet count) and experimental groups (mild and moderate thrombocytopenia). Pairwise comparison was performed using the Wilcoxon rank-sum test, Student's t-test or Fisher's exact test where appropriate. Multivariable logistic regression was used to determine the relationship between mild and moderate thrombocytopenia and the main outcome measures. Main Outcome Measures: Postoperative transfusion, infectious morbidity, readmission, reoperation, operating time and duration of hospitalization. Results: Moderate thrombocytopenia was associated with an increased risk of perioperative transfusion $(\mathrm{aOR}=2.87,95 \% \mathrm{CI}: 1.96-4.21)$ and reoperation (aOR=4.03, 95\% CI: 1.94-17.33) while mild thrombocytopenia was not. The risk of infection increased with both mild and moderate thrombocytopenia, $(\mathrm{aOR}=1.38,95 \% \mathrm{CI} 1.12-1.69)$ and $(\mathrm{aOR}=2.00,95 \% \mathrm{CI}: 1.23-3.22)$. Thrombocytopenia did not increase the risk of readmission, prolonged hospitalization or longer operating time. Conclusion: Thrombocytopenia is associated with increased infectious morbidity after hysterectomy, and moderate thrombocytopenia is associated with an increased risk of perioperative transfusion and reoperation.
\end{abstract}

\section{Hosted file}

thrombocytopenia manuscript final 5.18.2020.docx available at https://authorea.com/users/ 324612/articles/452769-are-patients-with-thrombocytopenia-at-higher-risk-for-adverseoutcomes-after-hysterectomy-for-benign-indications

\section{Hosted file}

figure 1 platelets.docx available at https://authorea.com/users/324612/articles/452769-arepatients-with-thrombocytopenia-at-higher-risk-for-adverse-outcomes-after-hysterectomyfor-benign-indications 